\section{Fading competency of cytogenetic diagnostic laboratories: the alarm bell has started to ring}

European Journal of Human Genetics (2017) 25, 273-274; doi:10.1038/ejhg.2016.177; published online 21 December 2016

\section{Sir,}

Clinical cytogenetics aims at the identification of chromosomal abnormalities by microscopic observation of metaphase chromosomes, known as karyotyping. Technical innovations such as arrays have replaced karyotyping as the first tier test for the identification of pathogenic genomic imbalances in referrals of intellectual disability and congenital anomalies. ${ }^{1,2}$ It is likely that in the near future, wholegenome sequencing will become the first tier test for such patients, which has the advantage of combining in a single test the identification of pathogenic mutations and imbalances. ${ }^{3}$ These exciting developments have caused a growing need for technicians and laboratory geneticists with specialized training in molecular genetics, and a shift from the microscope to DNA sequencing and interpretation of DNA variants.

The hidden danger of this shift is that the competency of laboratories offering cytogenetic services may fade away. Cytogenetic analysis will still be required as a second line test where the mechanism leading to the chromosomal rearrangement or clonal abnormalities need to be ascertained for patient and/or family management. The 2016 online external quality assessment (EQA) of postnatal karyotyping by the Cytogenetic EQA Service (CEQAS, www.ceqas.org) now provides the first evidence that this danger is imminent and will lead to incorrect clinical diagnoses. The case in point concerned a male who was referred for karyotyping because of hypogonadism and infantile genitalia. He had a mosaic karyotype with about equal proportions of 46,X,idic(Y)(q11.?21) and 45,X metaphases in lymphocytes from peripheral blood. As can be seen in Figure 1, the Y chromosome was unusually short and looked symmetric. Fluorescence in situ hybridization showed that two copies of the SRY gene were present, located at the terminal ends of each arm of the idic $(Y)$, and that two DYZ3 loci (centromeres) were present. There was no a

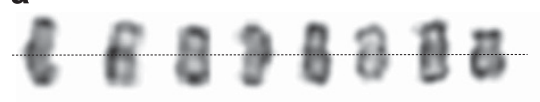

b

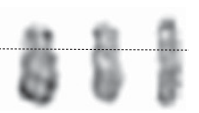

Figure 1 The idic(Y)(q11.?21) chromosome from a male with hypogonadism that was mistaken by $\sim 30 \%$ of participating laboratories for a normal $Y$ chromosome. The karyotype was 46,X,idic(Y)(q11.?12)[17/]/45,X[13]. ish idic (Y)(SRY++).nuc ish(DYZ3×2)[60/100],(DYZ1x0)[200]. (a) Representative idic (Y) chromosomes, each from a different metaphase. The dashed line represents the axis of symmetry. (b) For comparison, a structurally normal $Y$ chromosome is shown. The dashed line is at the position of the centromere. signal for DYZ1 (band Yq12) in 200 interphase nuclei investigated. Thus, there was no evidence for a normal Y chromosome in this male. Nevertheless, 48 of the 164 laboratories $(29.3 \%)$ that participated in this EQA reported a 45,X/46,XY mosaic karyotype, and 3 laboratories (1.8\%) reported a $\operatorname{del}(\mathrm{Y})(\mathrm{q} 11 . ? 21)$ instead of $\operatorname{idic}(\mathrm{Y})(\mathrm{q} 11 . ? 21)$. In total, 51 participants $(31.1 \%)$ failed to identify the abnormality correctly, an unprecedented high number.

An interpretation of this case as $45, \mathrm{X} / 46, \mathrm{XY}$ causes an incorrect clinical diagnosis to be made, since it leads to the wrongful assertions that the male fertility genes on the long arm of the Y chromosome are present and that spermatogenesis would be possible. The abnormal Y chromosome contains two copies of the short arm and the proximal part of the long arm of the Y chromosome and lacks the more distal long arm material. In this particular example both array and DNA sequencing-based methods are unable to correctly identify the genomic abnormality because a distinction between a mosaic idic(Y) and a non-mosaic del( $\mathrm{Y})$ would be impossible. In addition, the presence of 45,X cells could only be detected by microscopic observation of multiple, individual metaphases. Such idic(Y) chromosomes arise de novo by crossover between sister chromatids in the long arm of the Y-chromosome. The crossover takes place within one of the eight long palindromic DNA sequences in the long arm, each sharing $>99 \%$ sequence identity. ${ }^{4}$ Thus, current methods for wholegenome paired-end sequencing would probably miss the breakpoint because of the repetitive nature of the surrounding DNA sequences. The position of the exchange defines the axis of symmetry within the $\operatorname{idic}(\mathrm{Y})$, and also the extent of loss of genes on the long arm that are required for spermatogenesis. In this particular $\operatorname{idic}(\mathrm{Y})(\mathrm{q} 11 . ? 12)$ chromosome the point of symmetry in the long arm is relatively close to the centromere, leading to infertility through loss of $A Z F b$ and $A Z F C$, and perhaps also $A Z F a{ }^{5}$ This explains the hypogonadism in the patient and leads to the conclusion that spermatogenesis is absent. Therefore, it is inappropriate that several participating laboratories stated that this patient could have children through the application of artificial reproduction techniques. ${ }^{6,7}$

The fact that one in three laboratories failed this test is alarming evidence that cytogenetic proficiency has started to fade away. The basic skill that was on test in this EQA was the identification of a structurally abnormal G-banded chromosome, not the detection of a tiny deletion at the lower range of microscopic resolution. The morphological evaluation of human metaphase chromosomes requires a specialized training period of several years during which an adequate number of cases must be analyzed (see Appendix for examples). This assures that aspiring laboratory specialists are familiar with the human karyotype and are able to correctly identify any rare, exceptional chromosomal abnormality. In addition, they must gather sufficient experience to be competent to report such cases according to international guidelines. ${ }^{8}$ The training required for registration as a clinical laboratory geneticist varies between countries. For example, the training program of the Canadian College of Medical Geneticists (www.ccmg-ccgm.org) requires that at least 100 cases are analyzed in the laboratory and over 200 cases are evaluated and reported during a 2-year period. Also in the United States of America a specialized 2-3 year training program exists. ${ }^{9}$ In the United Kingdom there is a combined 3-year training program that includes basic cytogenetics, molecular genetics and some aspects of pathology. In The Netherlands, a 4-year training program, including the reporting of a minimum number of 1000 cases, was replaced in 2013 by a program that 
combines cytogenetics, molecular genetics, biochemical genetics and oncogenetics as one profession (www.vkgl.nl). This novel program has been approved by the European Society of Human Genetics (www. eshg.org) as a template for other countries of the European Union, ${ }^{9}$ but allows for only 3 months of training in the cytogenetic laboratory without specifying a minimum number of cases that must be analyzed and reported (www.vkgl.nl). The result of the 2016 postnatal bloods EQA rings an alarm bell for cytogenetic competency. Ensuring the competencies of laboratory personnel is an important part of quality assurance. Laboratory directors and board members of societies for human genetics now face the responsibility to ensure that sufficient numbers of candidates enter the training programs, and that the competencies of staff members involved in karyotyping are ensured. Our finding also provides evidence for the importance of participating in schemes for EQA.

\section{CONFLICT OF INTEREST}

The authors declare no conflict of interest.

\section{ACKNOWLEDGEMENTS}

We are indebted to Bettina Quellhorst-Pawley for expert technical and organizational skills, and we thank Wigard Kloosterman for discussion about the limitations of paired-end sequencing methods.

Ron Hochstenbach ${ }^{1}$, Anna Slunga-Tallberg ${ }^{2}$, Caroline Devlin ${ }^{3}$, Giovanna Floridia ${ }^{4}$, Marta Rodríguez de Alba $^{5}$, Shama Bhola ${ }^{6}$,

Katrina Rack $^{7}$ and Ros Hastings ${ }^{7}$

${ }^{1}$ Department of Genetics, University Medical Centre Utrecht, Utrecht, The Netherlands;

${ }^{2}$ HUSLAB Laboratory of Genetics, Hus, Finland;

${ }^{3}$ West of Scotland Genetic Services, Queen Elizabeth University Hospital, Glasgow, UK;

${ }^{4}$ Centro Nazionale Malattie Rare, Istituto Superiore di Sanità, Rome, Italy;

${ }^{5}$ Servicio de Genética Clínica, Fundación Jiménez Díaz, Madrid, Spain;

${ }^{6}$ Department of Clinical Genetics, VU University Medical Center, Amsterdam, The Netherlands;

${ }^{7}$ Women's Centre, Oxford University Hospital NHS Trust, Oxford, UK E-mail: p.f.r.hochstenbach@umcutrecht.nl

1 Hochstenbach R, van Binsbergen E, Engelen J et al: Array analysis and karyotyping: workflow consequences based on a retrospective study of 36,325 patients with idiopathic developmental delay in the Netherlands. Eur J Med Genet 2009; 52 : $161-169$

2 Miller DT, Adam MP, Aradhya S et al: Consensus statement: chromosomal microarray is a first-tier clinical diagnostic test for individuals with developmental disabilities or congenital anomalies. Am J Hum Genet 2010; 86: 749-764.
3 Hehir-Kwa JY, Pfundt R, Veltman JA: Exome sequencing and whole genome sequencing for the detection of copy number variation. Expert Rev Mol Diagn 2015; 15: $1023-1032$.

4 Lange J, Skaletsky H, van Daalen SK et al: Isodicentric $Y$ chromosomes and sex disorders as byproducts of homologous recombination that maintains palindromes. Cell 2009; 138: 855-869.

5 Krausz C, Chianese C, Giachini C, Guarducci E, Laface I, Forti G: The Y chromosomelinked copy number variations and male fertility. J Endocrinol Invest 2011; 34: 376-382.

6 Brandell RA, Mielnik A, Liuotta D et al: AZFb deletions predict the absence of spermatozoa with testicular sperm extraction: preliminary report of a prognostic genetic test. Hum Reprod 1998; 13: 2812-2815.

7 Krausz C, Quintana-Murci L, McElreavey K: What is the clinical prognostic value of $Y$ chromosome microdeletion analysis? Hum Reprod 2000; 15: 1431-1434.

8 Claustres M, Kožich V, Dequeker $\mathrm{E}$ et al: Recommendations for reporting results of diagnostic genetic testing (biochemical, cytogenetic and molecular genetic). Eur J Hum Genet 2010; 22: 160-170.

9 Zhang H, Yu J, Ming Q, Bao L, Wu B-L, Li P: On the globalization and standardization of medical genetics and genomics as clinical and laboratory specialities. N A J Med Sci 2014; 7: 194-198.

\section{APPENDIX}

Internet resources for training programs in clinical cytogenetics

Canada

Canadian College of Medical Geneticists. https://www.ccmg-ccgm.org/ images/Training/Cytogenetics/Cytogenetic_Training_Guidelines_2014. pdf

\section{European Union}

European Society of Human Genetics/European Board of Medical Genetics. https://www.eshg.org/fileadmin/eshg/EBMG/CLG/Core-Curriculum_2015.pdf

The Netherlands (since 2013)

Vereniging voor Klinisch Genetische Laboratorium Diagnostiek. http://www.vkgl.nl/docs/Opleidingseisen_laboratoriumspecialist_Klinische_Genetica.pdf

The Netherlands (until 2013)

Vereniging voor Klinisch Genetische Laboratorium Diagnostiek. http://www.vkgl.nl/docs/Samenvatting_specifieke_opleidingseisen_oude_stijl.pdf

\section{United Kingdom}

Association for Clinical Cytogenetics. http://www.cytogenetics.org.uk/ training/clinical_scientist_training_programme.html

\section{United States of America}

American Board of Medical Genetics and Genomics. http://www. abmgg.org/pages/training_options.shtml 